American Journal of Applied Science 2 (4): 832-835, 2005

ISSN 1546-9239

(C) Science Publications, 2005

\title{
System Availability in the Presence of Estimating Common-Cause Time-Varying Failure Rates
}

\author{
M.A. El-Damcese and Kh. A. Abd Alttif \\ Department of Mathematics, Faculty of Science, Tanta University, Tanta, Egypt
}

\begin{abstract}
This study presents a method for calculating the availability of a system depicted by availability block diagram, with identically distributed components, in the presence of estimating common cause hazard, we use the Marshall and Olkin formulation of the multivariate exponential distribution. That is, the components are subject to failure by Poisson failure processes that govern simultaneous failure of a specific subset of the components. A model is proposed for the analysis of systems subject to common-cause failures that are not considered to have a constant rate but that are assumed to obey a uniqueness of maximum likelihood estimators of the 2-parameter Weibull distribution. The method for calculating the system availability requires that a procedure exists for determining the system availability from component availabilities, under the statistically independent component assumption. The study includes an example to illustrate the method.
\end{abstract}

Key words: System Availability, Component Availabilities, Common-cause Failures

\section{INTRODUCTION}

Common-Cause (CC) hazards are the failure of multiple components due to a single occurrence or condition. For example, contaminate fluid causes two pumps to fail that are operated in "parallel". In this event, the availability of the "parallel" configuration with redundancy is less than a similar configuration with statistically independent components.

In this study, $\mathrm{CC}$ hazard is simultaneous hazards of multiple components due to a CC.

Most CC failure models assume that the shocks have constant (time-independent) rates of occurrence, leading to variants of the multivariate exponential distribution $^{[1-4]}$.

Many parameterization has been developed ${ }^{[5]}$, yet most of them are equivalent to (or special cases of) the general multivariate exponential model ${ }^{[6]}$.

There are two fundamentally different approaches for incorporating $\mathrm{CC}$ failure into system analysis: explicit and implicit method ${ }^{[7,8]}$.

The component failure probability density function could be described by different models, such as the Weibull distribution calculated from either complete failure data or from the behavior of the parameter Maximum Likelihood Estimates (MLE) of a 2parameter Weibull distribution ${ }^{[9]}$.

It is the main objective of the present study to utilize the hazard rates, extracted from operational experience, to calculate the availability of a system depicted by an availability block diagram with Weibull distribution components, in the presence of commoncaused hazards. Availability formulae for a configuration of a definite number of components are provided.
Uniqueness of MLE of the 2-parameter Weibull Distribution: We select an appropriate hazard rate for each constituent component in the system and evaluate its characteristic parameters. The function for the reliability of each component can then be easily derived.

The hazard function of a component following a 2parameter Weibull distribution can be described by:

$h_{j}(t)=\frac{\beta_{j} t^{\beta_{j-1}}}{\alpha_{j}^{\beta_{j}}}, j=1,2, \ldots, n$

The likelihood function is:

$$
\begin{aligned}
& \mathrm{L}=\prod_{\mathrm{i}=1}^{\tau} \mathrm{f}\left(\mathrm{t}_{\mathrm{i}}\right) \prod_{\mathrm{i}=\tau+1}^{\mathrm{m}} \mathrm{R}\left(\mathrm{t}_{\mathrm{i}}\right) \\
& =\left\{\prod_{\mathrm{i}=1}^{\tau} \frac{\beta_{\mathrm{j}}}{\alpha_{\mathrm{j}}^{\beta_{\mathrm{j}}}} \mathrm{t}_{\mathrm{i}}^{\beta_{\mathrm{i}-1}} \exp \left[-\left(\mathrm{t}_{\mathrm{i}} / \alpha_{\mathrm{j}}\right)^{\beta_{\mathrm{j}}}\right]\right\} \\
& \left\{\prod_{\mathrm{i}=\tau+1}^{\mathrm{m}} \exp \left[-\left(\frac{\mathrm{t}_{\mathrm{i}}}{\alpha_{\mathrm{j}}}\right)^{\beta_{\mathrm{j}}}\right]\right\}
\end{aligned}
$$

The partial derivatives of the natural $\log$ of the likelihood function are:

$$
\begin{aligned}
& \beta_{j}=1 /\left[\frac{\sum_{\mathrm{i}=1}^{\mathrm{m}} \mathrm{t}_{\mathrm{i}}^{\beta_{\mathrm{j}}} \ln \left(\mathrm{t}_{\mathrm{i}}\right)}{\sum_{\mathrm{i}=1}^{\mathrm{m}} \mathrm{t}_{\mathrm{i}}^{\beta_{\mathrm{j}}}}-\frac{\sum_{\mathrm{i}=1}^{\tau} \ln \left(\mathrm{t}_{\mathrm{i}}\right)}{\tau}\right] \\
& \alpha_{\mathrm{j}}=\left(\frac{\sum_{\mathrm{i}=1}^{\mathrm{m}} \mathrm{t}_{\mathrm{i}}^{\beta_{\mathrm{j}}}}{\tau}\right)^{1 / \beta_{\mathrm{j}}}
\end{aligned}
$$


Since (3.1) involves $\beta_{j}$ alone, iterative methods are usually directed at solving (3.1); and substituting the resulting value into (3.2) to find $\alpha_{j}$.

For censorting, $t_{i}$ is a recorded failure time for $i \leq \tau$ and $t_{i}=t_{s}$ for $\tau+1 \leq i \leq m$. When all $t t_{i}(I=1,2, \ldots, m)$ are available, the data are complete; complete data are a special case of right censoring for $\tau=\mathrm{m}$.

Our empirical investigations suggest that choosing ${ }^{[9]}$ :

$\hat{\beta}_{\mathrm{j}}=\left[\frac{\mathrm{V}+(\mathrm{V}-(\tau / \mathrm{m}) \mathrm{V})}{2}\right]^{-1}$

Where:

$$
\begin{aligned}
& \mathrm{V}=\lim _{\beta \rightarrow \infty}\left[\frac{\sum_{\mathrm{i}=1}^{\mathrm{m}} \mathrm{t}_{\mathrm{i}}^{\beta_{\mathrm{j}}} \ln \left(\mathrm{t}_{\mathrm{i}}\right)}{\sum_{\mathrm{i}=1}^{\mathrm{m}} \mathrm{t}_{\mathrm{i}}^{\beta_{\mathrm{j}}}}-\frac{\sum_{\mathrm{i}=1}^{\tau} \ln \left(\mathrm{t}_{\mathrm{i}}\right)}{\tau}\right] \\
& =\ln \left(\mathrm{t}_{\mathrm{s}}\right)-\frac{\sum_{\mathrm{i}=1}^{\tau} \ln \left(\mathrm{t}_{\mathrm{i}}\right)}{\tau}
\end{aligned}
$$

works well. For complete data, this approximation simplifies to $\hat{\beta} \simeq 2 / \mathrm{V}$; (4) provides a quick approximation to $\hat{\beta}$ and can be used as an initial estimate of $\hat{\beta}$ for iterative MLE routines.

Component Availability Model: Figure 1 is the state transition diagram for the 1-component availability model:

States $1 . \mathrm{x}_{1} \quad$ 2. $\overline{\mathrm{x}}_{1}$

The general relation to the state probabilities as a function of time is:

$\left[\begin{array}{l}\dot{P}_{1}(t) \\ \dot{P}_{2}(t)\end{array}\right]=\left[\begin{array}{cc}-h(t) & \mu \\ h(t) & -\mu\end{array}\right]\left[\begin{array}{l}P_{1}(t) \\ P_{2}(t)\end{array}\right]$

The first equation of (6), after much tedious algebra, the result is:

$$
\begin{aligned}
& P_{1}(t)=\exp \left[-\int_{0}^{t}(h(t)+\mu) d t\right] \\
& {\left[1+\mu\left(\int_{0}^{t} \exp \left[-\int_{0}^{t}(h(t)+\mu) d t\right]\right)\right]}
\end{aligned}
$$

In general, for the given:

$$
\mathrm{h}(\mathrm{t})=\mathrm{h}_{\mathrm{j}}(\mathrm{t})=\frac{\beta_{\mathrm{j}}}{\alpha_{\mathrm{j}}^{\beta_{\mathrm{j}}}} \mathrm{t}^{\beta_{\mathrm{j}-1}} \text {, and } \mu=\mu_{\mathrm{j}} \text {. }
$$

$A_{j}(t)=P_{1}(t)(j=1,2, \ldots, n)$ is calculate with :

$$
\begin{aligned}
& \mathrm{A}_{\mathrm{j}}(\mathrm{t}) \cong\left(\mu_{\mathrm{j}} \mathrm{t}\right)\left[1+\frac{1}{2}\left(\mu_{\mathrm{j}} \mathrm{t}\right)+\frac{1}{6}\left(\mu_{\mathrm{j}} \mathrm{t}\right)^{2}+\left(\frac{1}{\beta_{\mathrm{j}}+1}+\frac{\mu_{\mathrm{j}} \mathrm{t}}{\beta_{\mathrm{j}}+2}\right)\left(\mathrm{t} / \alpha_{\mathrm{j}}\right)^{\beta_{\mathrm{j}}}\right. \\
& \left.+\frac{\left(\mathrm{t} / \alpha_{\mathrm{j}}\right)^{2 \beta_{\mathrm{j}}}}{2\left(2 \beta_{\mathrm{j}}+1\right)}\right] \exp \left[-\left[\mu_{\mathrm{j}} \mathrm{t}+\left(\mathrm{t} / \alpha_{\mathrm{j}}\right)^{\beta_{j}}\right]\right]+\exp \left[-\left[\mu_{\mathrm{j}} \mathrm{t}+\left(\mathrm{t} / \alpha_{\mathrm{j}}\right)^{\beta_{j}}\right]\right] \\
& \mathrm{j}=1,2, \ldots, \mathrm{n}
\end{aligned}
$$

System Availability Analysis with Common-cause Hazards: $A_{n}^{(1)}(t)$ is the probability that the specified component is operating at time t, i.e. The probability that none of the processes that govern the simultaneous failure of $j$ component, $j=1,2---, n$, includes the specific component. Based on the S-independence of the Poisson processes, we have:

$A_{n}^{(1)}(t)=\prod_{j=1}^{n}\left[A_{j}(t)\right]^{\left(\begin{array}{l}n-1 \\ j-1\end{array}\right)}$

The probability that a specific group of $\mathrm{k}$ components out of $\mathrm{n}$-component system are all good is:

$\mathrm{A}_{\mathrm{n}}^{(\mathrm{k})}(\mathrm{t})=\operatorname{Pr}\left\{\mathrm{S}_{1} \cap \mathrm{S}_{2} \cap \mathrm{S}_{3} \cap \ldots \cap \mathrm{S}_{\mathrm{K}} ; \mathrm{t}\right\}$

$=\operatorname{Pr}\left\{\mathrm{S}_{1} ; \mathrm{t}\right\} \mathrm{P}_{\mathrm{r}}\left\{\mathrm{S}_{2} / \mathrm{S}_{1} ; \mathrm{t}\right\} \mathrm{P}_{\mathrm{r}}$

$\left\{\mathrm{S}_{3} / \mathrm{S}_{1}, \mathrm{~S}_{2} ; \mathrm{t}\right\} \ldots \mathrm{P}_{\mathrm{r}}\left\{\mathrm{S}_{\mathrm{k}} / \mathrm{S}_{1}, \mathrm{~S}_{2}, \ldots, \mathrm{S}_{\mathrm{k}-1} ; \mathrm{t}\right\}$

$=\mathrm{A}_{\mathrm{n}}^{(1)}(\mathrm{t}) \mathrm{A}_{\mathrm{n}-1}^{(1)} \cdots \mathrm{A}_{\mathrm{n}-\mathrm{k}+1}^{(1)}(\mathrm{t})$

$=\prod_{r=n-k+1}^{n} A_{r}^{(1)}(t)$

These formulas were originally derived from Kyung $^{[10]}$ for constant hazard rates; similar arguments are valid for time-varying failure rates ${ }^{[11]}$.

The results are $A_{c}(t)$ and $A_{s}(t)$ in terms of availabilities $A_{j}(t)$.

Illustrative Example: Let the given Fig. 2 is the availability block-diagram.

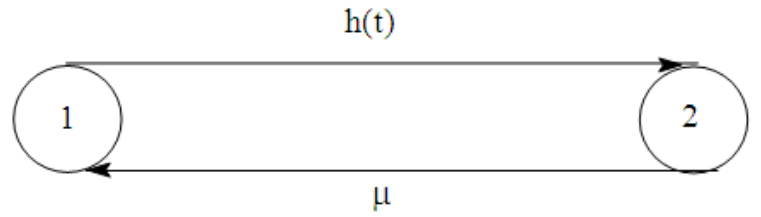

Fig. 1: Component Availability State-transition Diagram

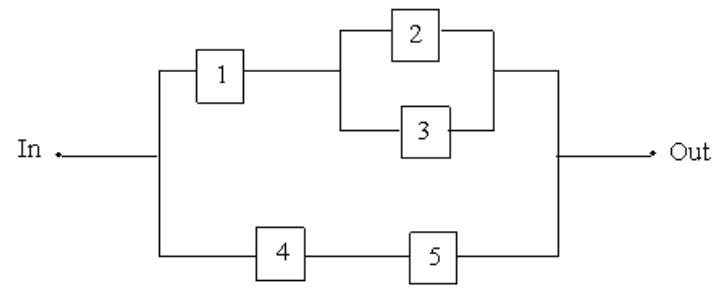

Fig. 2: Availability Block-Diagram for Example 
Table 1: Compute Estimate of the Parameters $\beta_{\mathrm{j}}$ and $\alpha_{\mathrm{j}}$, and Assuming Repair Rates $\mu_{\mathrm{j}}$ for Number of Simultaneous Failures Number of Simultaneous Failures

\begin{tabular}{|c|c|c|c|c|c|c|c|c|}
\hline \multicolumn{9}{|c|}{ Ordered Failure Time $t_{i j}$} \\
\hline \multicolumn{5}{|c|}{ For $\mathrm{j}=1,2, \ldots, 5$ and $\mathrm{i}=1,2, \ldots, 10$} & $\mathrm{~V}_{\mathrm{j}}$ & $\beta_{\mathrm{j}=2} / \mathrm{V}_{\mathrm{j}}$ & $\alpha_{j}=\left(\sum^{10} t_{i j}^{\beta_{j}} / 10\right)^{1 / \beta_{j}}$ & $\mu_{j}$ \\
\hline j & 123 & $\begin{array}{ll}4567 & 8\end{array}$ & 9 & 10 & & & & \\
\hline 1 & 3758 & 115136152165185213 & & & 0.6819 & 2.42 & 138.07 & 0.06 \\
\hline 2 & 3143 & 738296101111195 & & & 0.948 & 2.12 & 97.220 & 0.05 \\
\hline 3 & 2735 & 96101131145199222 & & & 0.884 & 2.26 & 128.41 & 0.04 \\
\hline 4 & 2432 & 798998120180235 & & & 1.117 & 1.79 & 111.66 & 0.03 \\
\hline 5 & 1826 & 7793108135220253 & & & 1.216 & 1.64 & 118.84 & 0.02 \\
\hline
\end{tabular}

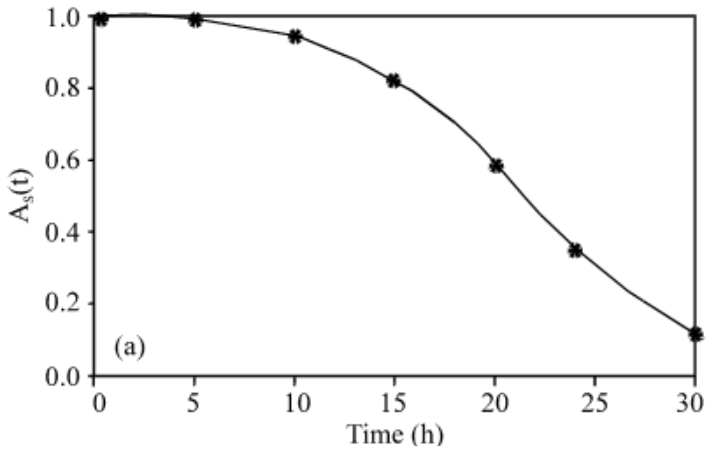

Fig. 3a: System Availability Plot Response for i.i.d Components

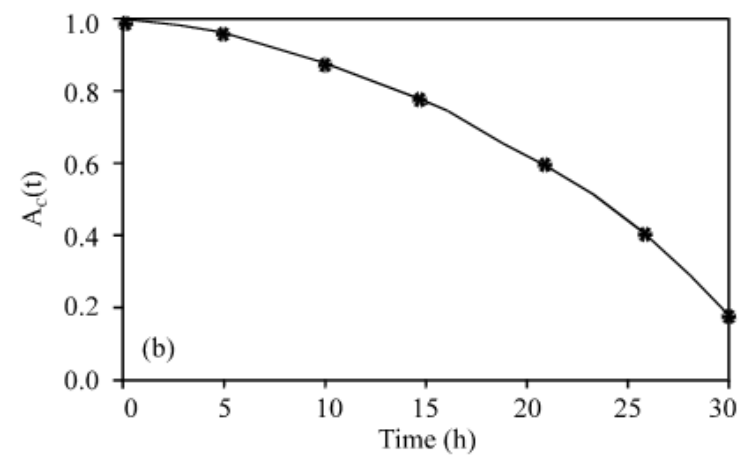

Fig. 3b: System Common-cause Availability Variation by Time

For identically distributed components with statistically-independent failure processes, the availability $A_{S}(t)$ of the whole system can then be evaluated as:

$$
A_{S}(t)=3 A^{2}(t)-A^{3}(t)-2 A^{4}(t)+A^{5}(t)
$$

For comparison purposes, the one-component availability remains at the value of a component in the five-component common-causc system, but the system consists statistically-independent and identically distributed (i.i.d) components that are, calculate $\mathrm{A}_{S}(\mathrm{t})$ when $\mathrm{A}(\mathrm{t})=\mathrm{A}_{5}^{(1)}(\mathrm{t})$ in equation (11)

The resulting availability neglects, the system effects of common-cause failures and represents the prediction of a practitioner assessing all failures causes against a component, but assuming a "statisticallyindependence" model. In that case, we have:

$$
\begin{aligned}
& A_{5}^{(1)}(t)=\prod_{j=1}^{5}\left[A_{j}(t)\right]^{\left(\begin{array}{c}
4 \\
j-1
\end{array}\right)} \\
& =A_{1}(t) A_{2}^{4}(t) A_{3}^{6}(t) A_{4}^{4}(t) A_{5}(t)
\end{aligned}
$$

When the identically distributed components have common-cause failures, we have:

$$
A_{c}(t)=3 A_{5}^{(2)}(t)-A_{5}^{(3)}(t)-2 A_{5}^{(4)}(t)+A_{5}^{(5)}(t)
$$

Where:

$$
\mathrm{A}_{5}^{(\mathrm{k})}(\mathrm{t})=\prod_{\mathrm{r}=6-\mathrm{k}}^{5} \mathrm{~A}_{\mathrm{r}}^{(1)}(\mathrm{t}), \mathrm{k}=2,3,4,5
$$

Making use of the data provided and assumed Table 1, the available functions of Eqs. (11) and (12) in terms of $\mathrm{A}_{5}^{(1)}(\mathrm{t})$, and $\mathrm{A}_{5}^{(\mathrm{k})}(\mathrm{k}=2,3,4,5)$ respectively vary with time as shown in Fig. 3 (a) and 3 (b). Thus, for this case, the system availability, assuming common-cause, failures, is appreciably lower than the i.i.d system availability.

\section{Notation:}

$\mathrm{n} \quad=$ Number of components in the system;

$\mathrm{k}$ =Number of good components that allow the system to operate;

$A_{j}(t)=$ Availability of component $\mathrm{j}$ at time $\mathrm{t}$;

$\mathrm{A}_{\mathrm{c}}(\mathrm{t}) \quad=$ System availability at time $\mathrm{t}$ with $\mathrm{CC}$ hazard;

$\mathrm{A}_{\mathrm{s}}(\mathrm{t}) \quad=$ System availability without $\mathrm{CC}$ hazard;

$\mathrm{A}_{\mathrm{n}}{ }^{(\mathrm{k})}(\mathrm{t})=$ Probability that all the components of a specific k-component subset out of an ncomponent system are operating at time $\mathrm{t}$;

$\mathrm{h}_{\mathrm{j}}(\mathrm{t})=$ Hazard rate; $\mathrm{h}_{\mathrm{j}}(\mathrm{t}) \mathrm{dt}=$ conditional probability of an event failing specific $\mathrm{j}$ components, and no others, during $(\mathrm{t}, \mathrm{t}+\mathrm{dt})$, given no such event during $(0, \mathrm{t})$;

$h_{j}(t)=\int_{0}^{t} h_{j}(u) d u:$ cumulative hazard function; 
$\left(\begin{array}{l}n \\ j\end{array}\right)=$ Number of combinations of $j$ items out of possible $\mathrm{n}$ items.

$\alpha_{\mathrm{j}}, \beta_{\mathrm{j}} \quad=$ Positive [scale, shape] parameter of component $\mathrm{j}$

$\mathrm{m}=$ Number of items tested;

$\mathrm{t}_{\mathrm{i}} \quad=$ Failure time of item $\mathrm{i}$ under test;

$\mathrm{R}\left(\mathrm{t}_{\mathrm{i}}\right)=$ Reliability of a single component at time $\mathrm{t}_{\mathrm{i}}$;

$\mathrm{F}\left(\mathrm{t}_{\mathrm{i}}\right) \quad=$ Probability density function of time $\mathrm{t}_{\mathrm{i}}$;

$\mathrm{t}_{\mathrm{s}} \quad=$ Maximum test time for censoring;

$\tau=$ Number of items that fail before $t_{s}$;

$\mathrm{P}_{\mathrm{j}}(\mathrm{t}) \quad=$ Individual state probabilities;

$\mu_{\mathrm{j}} \quad=$ Constant repair rate for component $\mathrm{j}$;

$\mathrm{S}_{\mathrm{i}} \quad=$ Event that component $\mathrm{i}$ is good.

\section{REFERENCES}

1. Marshall, A.W. and I. Olkin, 1967. A multivariate exponential distribution. J. Amer. Statistical Assoc., 62: 30-44.

2. Fleming, K.N., 1975. A reliability model for common mode failures in redundant safetysystems. Report GA-A 13284, General Atomic Company, San Diego.

3. Apostolakis, G.E., 1976. The effect of a certain class of potential common mode failures on the reliability of redundant systems. Nuclear System Reliability Engineering and Design, 36: 123-133.

4. Vesely, W.E., 1977. Estimating Common-cause Failure Probabilities in Reliability and Risk Analysis: Marshall-Olkin Specializations. Nuclear Systems Reliability Engineering and Risk Assessment (J.B. Fussell and G.R. Burdick, Eds.), pp: 314-341, Society of Industrial and Applied Mathematics.
5. Dhillon, B.S. and O. C. Anude, 1994. Commoncause failures in engineering systems: A review. Intl. J. Reliability, Quality and Safety Engg., 1: 103-129.

6. Vaurio, J.K., 1994. The theory and quantification of common-cause shock events for redundant standby systems. Reliability Eng'g and System Safety, 43: 289-305.

7. Fleming, K.N. and A. Mosfeh, 1985. Commoncause data analysis and implications in system modeling. Proc. Intl. Topical Meeting on Probabilistic Safety Methods and Applications, Feb. 24- Mar.1, pp: 3/1-3/12; EPRINP-3912-SR.

8. Jussi, K. Vaurio, 1998. An implicit method for incorporating common-cause failures in system analysis. IEEE Trans. Reliability, 47: 2.

9. Nicholas, R. Farnum, 1997. Uniqueness of maximum likelihood estimators of the 2-parameter Weibull distribution. IEEE Trans. Reliability, 46: 4.

10. Kyung, M. Gordon, 1986. System reliability in the presence of common-cause failures. IEEE Trans. Reliability R-35.

11. El-Damcese, M.A., 1996. Reliability of systems subject to common-cause hazards assumed to obey an exponential power model. Nuclear Eng'g and Design, 167: 85-90. 